\title{
Production of Liquid Biofuels from Microalgae Chlorella sp. via Catalytic Slow Pyrolysis
}

\author{
Bambang Sardi ${ }^{1}$, Rifa Fatwa Ningrum ${ }^{1}$, Vicky Aziz Ardiansyah ${ }^{1}$, Lailatul Qadariyah ${ }^{1}$, \\ Mahfud Mahfud ${ }^{1 *}$ \\ ${ }^{1}$ Department of Chemical Engineering, Institut Teknologi Sepuluh Nopember, Surabaya 60111, Indonesia
}

\begin{abstract}
This study investigates the effects of catalyst preparation techniques on the yield and quality of liquid biofuel produced from slow catalytic pyrolysis of microalgae Chlorella sp. using various catalysts, including acid catalysts (HZSM-5) and base catalysts (activated carbon). The effects of different temperatures, catalyst loading, and reaction time on the yield and quality of liquid biofuels, including chemical composition, density, and the resulting viscosity at the optimal variable, were investigated. The results showed that slow catalytic pyrolysis using $1 \mathrm{wt} . \%$ activated carbon catalyst, a temperature of $550^{\circ} \mathrm{C}$, and a reaction time of three hours produced a maximum yield of liquid biofuel at 50.38 wt.\% with high aromatic hydrocarbons, less oxygen and acid, a density of $0.88 \mathrm{~kg} / \mathrm{L}$, and a viscosity of $5.79 \mathrm{cSt}$ that satisfied specifications of biodiesel No. 2. Slow catalytic pyrolysis with a variety of catalyst types and catalyst preparation techniques affects the increase in yield and quality adjustment of liquid biofuel. The proposed technology can be further developed for commercial applications, replacing conventional diesel fuel.
\end{abstract}

Keywords: Activated carbon; Chlorella sp.; HZSM-5; Liquid biofuel; Slow catalytic pyrolysis

\section{Introduction}

Globally, $\mathrm{CO}_{2}$ emissions are a product of the consumption of fossil fuels, especially crude oil, as the primary energy source impacting climate change and global warming (Hosseini et al., 2019). One of the alternative renewable energy resources that can meet global demand is biomass in the form of third-generation biofuels (Alaswad et al., 2015). The third generation of biofuels, especially those derived from microalgae biomass, is an ideal source of raw materials and has advantages over the first and second generations biofuels in terms of cultivation, lipid composition, product yield, viscosity, density, and calorific value of biofuels (Mahfud et al., 2020; Shihab et al., 2020). However, the conversion efficiency of biofuel production from microalgae compared with biofuels from other biomass is still very low (Rizzo et al., 2013).

One of the thermochemical conversion methods to produce liquid biofuel (aka bio-oil) from microalgae biomass is pyrolysis (Yang et al., 2019). Studies related to pyrolysis have been reported in the literature. Supramono et al. (2016) investigated the co-pyrolysis of biomass and plastics (polypropylene). The results showed that adding polypropylene composition in the feed blend from 37.5 to $87.5 \mathrm{wt}$.\% increased the bio-oil yield from 25.8 to $67.2 \mathrm{wt}$.\%. The pyrolysis could also be used to fabricate advanced materials, such as 
as nanocomposites (Kusdianto et al., 2019) and fluorine-doped tin oxide (Yuwono et al., 2017).

The characteristics of microalgae Chlorella sp. as biofuel feedstock have been studied widely by many researchers. Hu et al. (2014) investigated the production of liquid bio-oil via fast catalytic pyrolysis from microalga Chlorella vulgaris using different catalysts and contents of activated carbon. They found that catalysts only affected the pyrolysis products. The maximum liquid and gaseous yield were achieved with activated carbon. Zainan et al. (2018) investigated slow catalytic pyrolysis of microalgae Chlorella vulgaris using $\mathrm{Ni}$ supported zeolite $(\mathrm{Si} / \mathrm{Al}=30)$. The effects of different temperatures and catalyst to algae ratio on bio-oil yield and quality were analyzed. They found that the optimal pyrolysis temperature for slow catalytic pyrolysis of Chlorella vulgaris was $500^{\circ} \mathrm{C}$ with high hydrocarbon production and low oxygenated and acid compounds in the oil. Also, a lower catalyst to algae ratio produced a higher bio-oil yield was observed. The catalyst preparation method did not affect the yield but affected the bio-oil composition. Oxygenated bio-oil compounds were lower for catalyst prepared using wet impregnation than catalyst prepared using ion-exchange at all temperature variations $\left(400^{\circ} \mathrm{C}\right.$ and $\left.500^{\circ} \mathrm{C}\right)$.

Although the studies mentioned above researched the Chlorella sp. as the bio-oil feedstock, studies on slow catalytic pyrolysis to increase the yield and quality of bio-oil from Chlorella sp. are still scarce in the literature, especially those using acid and base types of catalysts. In this study, we investigated the production of bio-oil (i.e., bio-oil yield) using various types of catalysts, including acid catalysts (HZSM-5) and base catalytic (activated carbon) with variations of catalyst treatment. The quality of bio-oil, including its chemical composition, density, and viscosity, at optimum conditions of catalyst treatment, temperature, and reaction time, was analyzed. The primary outcome of this study is expected to produce bio-oil that can easily meet the requirements of diesel fuel No. 2 in commercial applications.

\section{Methods}

\subsection{Materials}

Chlorella sp. was used in the form of phytoplankton culture obtained from free waters. The process was carried out in the Brackishwater Aquaculture Development Center (BADC) laboratory in Situbondo, East Java, with multilevel culture methods. Chlorella sp. starting with the preparation of tools and materials that have been sterilized, making Walne fertilizer and vitamins, isolation of Chlorella sp. on Petri dish as agar media, culture on the 10-mL test tube, culture on 250 mL Erlenmeyer, culture on 3-L glass bottles, and culture on a 10L carboy. An intermediate scale was started using Chlorella sp. derived from pure culture on a laboratory scale. The Chlorella sp. was maintained for approximately five days and reached the exponential phase on day 4. Harvesting for the intermediate scale at the BADC was conducted by removing the Chlorella sp. from the intermediate culture tank into the mass-scale culture tank. A mass-scale culture was conducted with a water volum of more than $1 \mathrm{~m} 3$. In addition to mass-scale culture, seedlings were also harvested to make powder. Harvesting was done by the chemical flocculant method using sodium hydroxide $(\mathrm{NaOH})$. The main characteristics of the dried Chlorella sp. are ash of $53.08 \mathrm{wt} . \%$, protein of $12.13 \mathrm{wt} . \%$, lipids of $12.41 \mathrm{wt} . \%$, fibers of $0.14 \mathrm{wt} . \%$, nitrogen-free extract of $2.74 \mathrm{wt} . \%$, and heating value of $1398.98 \mathrm{cal} / \mathrm{g}$. The greater the organic content of the feedstock, the greater the bio-oil that could be produced due to thermal decomposition within the pyrolysis process.

\subsection{Pyrolysis}

This study used a fixed bed reactor made of stainless steel, with a maximum heating 
temperature of $750^{\circ} \mathrm{C}$, and an insulated space to reduce heat transfer from the system. This reactor worked with thermal and catalytic pyrolysis processes. The temperature was measured and regulated by an electric heating source using an integral proposal model with an offset of $2^{\circ} \mathrm{C}$. The heating speed was $<1^{\circ} \mathrm{C} / \mathrm{s}$, categorized as slow pyrolysis under vacuum pressure (Pinput $=-7 \mathrm{mmH}_{2} \mathrm{O}$; Poutput $=-10 \mathrm{~mm} \mathrm{H}_{2} \mathrm{O}$ ) to isolate the contents from the presence of oxygen (Thahir et al., 2019). A schematic diagram of the experimental equipment is shown in Figure 1.

The experiment was carried out by inserting $200 \mathrm{~g}$ of Chlorella sp. into the reactor and catalyst according to the desired ratio. The sample was then heated in a reactor under vacuum conditions. Then the temperature setting was carried out according to the desired process conditions until the pyrolysis time was reached. Under specific temperature and time conditions, solid, liquid, and gaseous products will form. Next was the separation of the aqueous phase and organic phase using a separatory funnel and evaporating the moisture content still contained in the liquid product. The product was weighed and analyzed in the form of char, gas, organic fraction, and the aqueous fraction of the liquid product. The research was again carried out for other process variables. The process parameters reviewed in this study were temperature variations of $450^{\circ} \mathrm{C}, 500^{\circ} \mathrm{C}, 550^{\circ} \mathrm{C}$, and $600^{\circ} \mathrm{C}$. The amount of catalyst (HZSM- 5 and activated carbon) was $0 \mathrm{wt} . \%$ (non-catalyzed), $1 \mathrm{wt} . \%$, and $2 \mathrm{wt} . \%$. Variations in pyrolysis time were measured at $1,2,3$, and 4 hours. The catalyst types are non-catalyst, HZSM-5 catalyst (i.e., 1 wt.\%-2 wt.\%) and activated carbon catalysts (i.e., 1 wt.\%-2 wt.\%).

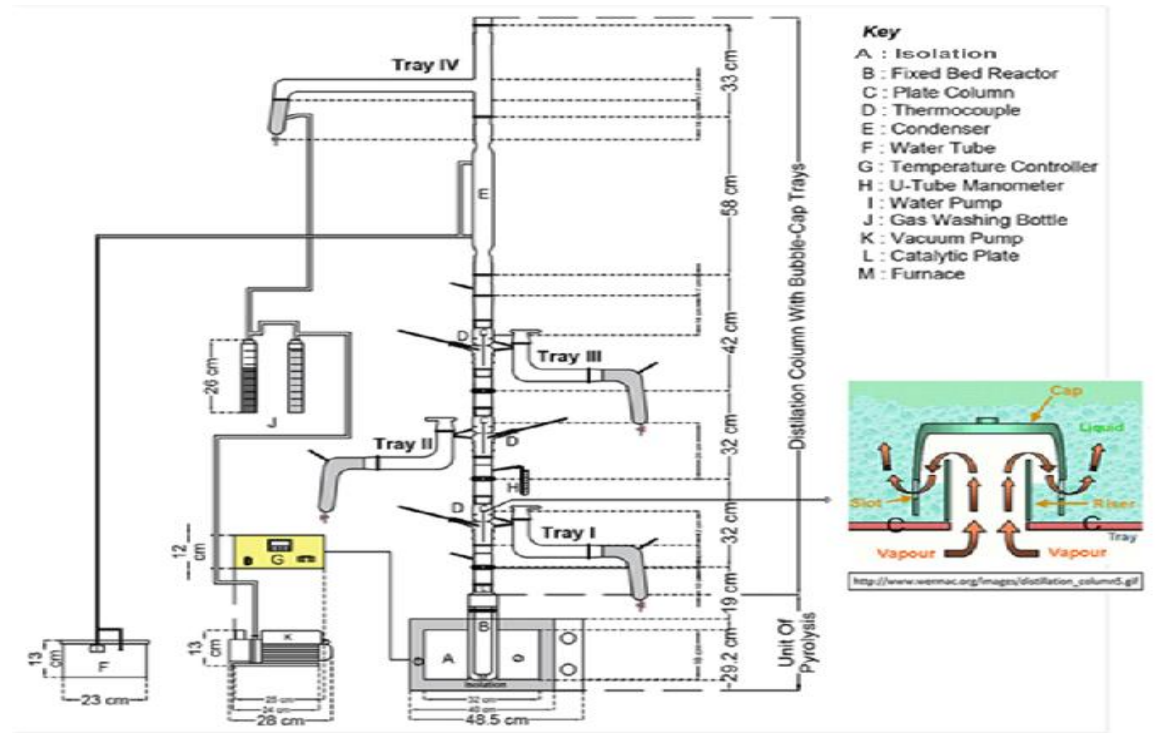

Figure 1 The slow catalytic pyrolysis

\subsection{Analysis of Liquid Biofuels}

The properties of the liquid biofuel product, which was composed of organic and aqueous fractions, were characterized by Fourier transform infrared (FTIR) analysis, and the density and viscosity were determined. The FTIR spectra were collected in a Nicolet Series II Magna-IR System 750 spectrometer, equipped with a liquid nitrogen-cooled mercury cadmium telluride (MCT) detector. The oil was deposited between two $\mathrm{NaCl}$ disks. The selected spectral range was $400-650 \mathrm{~cm}^{-1}$, with a resolution of $4 \mathrm{~cm}^{-1}$.

The density of the liquid biofuel was determined using a 5-mL size-specific gravity bottle pycnometer. The bottom of the flat bottle with a perforated stopper is borosilicate glass from Eisco Labs. The pycnometer test began with its cleaning and drying in an oven at $105^{\circ} \mathrm{C}$ for $15-30$ minutes, after which it was placed in a desiccator for $10-15$ minutes. 
The volume $\left(V_{\text {pycno }}\right)$ and the mass of the empty pycnometer $\left(\mathrm{M}_{\text {pycno }}\right)$ were recorded. The liquid biofuel was added to the pycnometer up above the neck, and the lid was placed until the liquid biofuel filled the capillary tube until it was full, ensuring that no air bubbles were present in it $\left(M_{\text {pycno }}+\right.$ fuel $)$. The density of the liquid biofuel $\left(\rho_{\text {fuel }}\right)$ was determined by the following equation:

$$
\rho_{\text {fuel }}=\frac{\left(M_{\text {pycno }}+\text { fuel }\right)-M_{\text {pycno }}}{V_{\text {pycno }}}
$$

The viscosity of the liquid biofuel was determined using the Ostwald viscometer (Thomas XXX80B1539 Borosilicate Glass Ostwald Oil Viscometer, with a 5-mL minimum sample), which measures the time taken for the liquid biofuel to pass through two points when flowing through the viscometer because of gravity. The viscometer was first calibrated with water, which has known time $\left(t_{\text {water }}\right)$, density $\left(\rho_{\text {water }}\right)$, and viscosity $\left(\eta_{\text {water }}\right)$. Its use began with piping the liquid biofuel into the viscometer and sucking it using a pushball until it crossed the two limits. Then, a stopwatch was prepared, the liquid biofuel was relaxed to the first limit, and the liquid biofuel time was calculated $\left(t_{f u e l}\right)$. The viscosity of the liquid biofuel $\left(\eta_{\text {fuel }}\right)$ was determined by the following equation:

$$
\eta_{\text {fuel }}=\eta_{\text {water }} \frac{t_{\text {fuel }} \times \rho_{\text {fuel }}}{t_{\text {water }} \times \rho_{\text {water }}}
$$

\section{Results and Discussion}

\subsection{Influence of Temperature on Pyrolysis Product Yields}

The relationship between the temperature and the liquid yield is shown in Figure 2 with a heating rate $<1^{\circ} \mathrm{C} / \mathrm{s}$. The higher the temperature $\left(450-550^{\circ} \mathrm{C}\right)$, the greater the increase in the liquid yield. The liquid yield consisted primarily of aqueous and organic fractions, resulting from the cracking process at $450-550^{\circ} \mathrm{C}$, to $550-600^{\circ} \mathrm{C}$. The highest liquid biofuel yield (50.38 wt.\%) is obtained at a temperature of $550^{\circ} \mathrm{C}$ with $1 \mathrm{wt} . \%$ activated carbon (base catalyst). These conditions are similar to what has been found by Dai et al. (2018), where the optimum temperature to produce the liquid yield is $550^{\circ} \mathrm{C}$ at 1 wt.\% activated carbon (base catalyst). The temperature of $600^{\circ} \mathrm{C}$ is the optimum temperature for the maximum gas yield (\%). The optimum temperature for the maximum char yield in variations of catalysts was 2 wt.\% HZSM-5 (acid catalysts) product and a maximum char yield of $72.16 \mathrm{wt} . \%$. The gas yield was inconsistent between $1.14 \mathrm{wt} . \%$ and 22.85 wt.\%.

An increase in the process temperature of $1 \mathrm{wt} . \%$ HZSM- 5 catalyst and $1 \mathrm{wt} . \%$ activated carbon catalyst caused a decrease in the char yield. This is because the primary decomposition of microalgae is greater at high temperatures; the secondary thermal decomposition of char occurred before it exited reaction conditions (Pattiya, 2011). If char was not separated rapidly from steam, heat-catalyzed cracking from primary organic vapor could occur at low temperatures (Pourkarimi et al., 2019). The increase in temperature caused a decrease in the char yield and an increase in the gas yield, the same result obtained by $\mathrm{Hu}$ et al. (2013). The temperature rise impacted the greater gas yield, owing to the secondary cracking of char and the pyrolysis vapor reaction (Pattiya et al., 2012). The effect of the reaction temperature on biofuel products with the $2 \mathrm{wt} \% \mathrm{HZSM}-5$ catalyst and 2 wt.\% activated carbon catalyst during slow pyrolysis provided larger char yields than the liquid and gas yields. An increase in the acid catalyst results in lower liquid biofuel due to char formation, and the maximum biofuel is obtained at the base catalyst. 


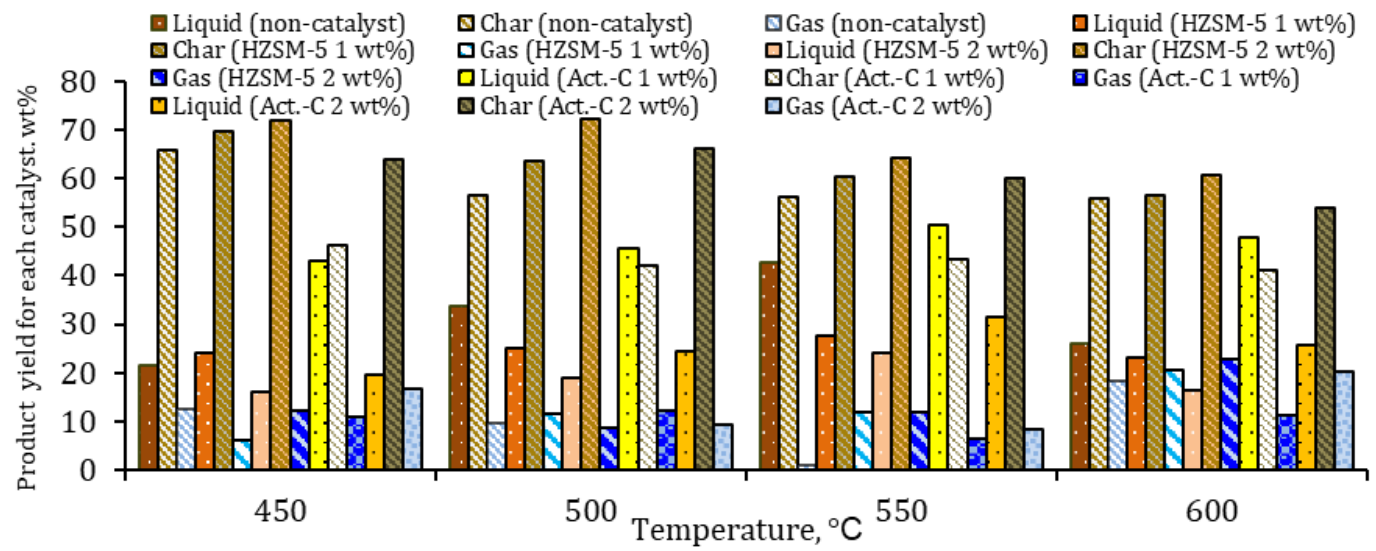

Figure 2 Effect of temperature on product yields

\subsection{Effect of Catalyst Amount on Pyrolysis Product Yields}

The amount of catalyst is a variable that plays a vital role in converting dried microalgae into biofuel products. In this study, a variation of catalyst concentration, including HZSM-5 catalyst ( $1 \mathrm{wt} . \%-2$ wt.\%) and activated carbon catalysts ( $1 \mathrm{wt.} \%-2 \mathrm{wt} . \%)$, were compared to the non-catalyst treatment with the use of $200 \mathrm{~g}$ of microalgae (dry weight). The relationship between each treatment of various catalysts and the liquid yield of bio-oil is shown in Figure 3.

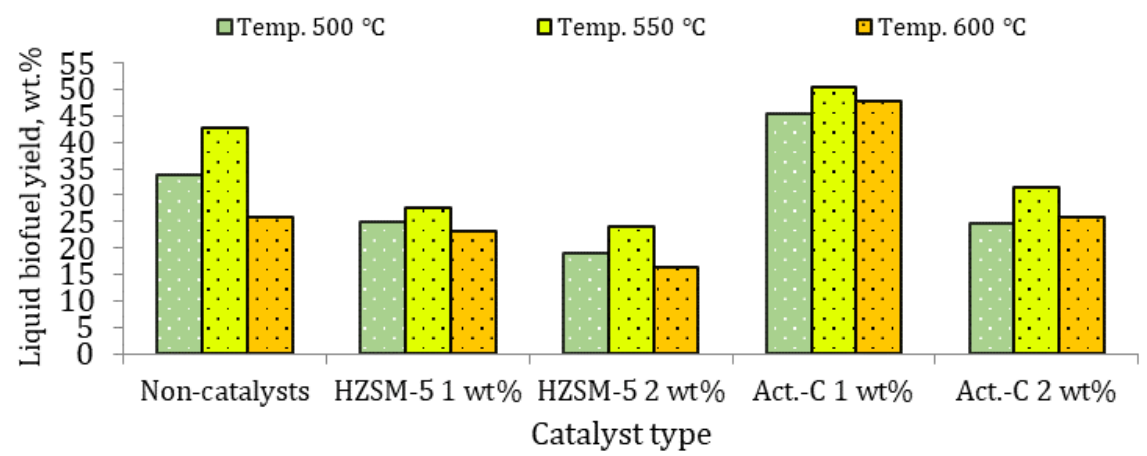

Figure 3 Effect of the catalyst on pyrolysis liquid yields

Figure 3 shows that when a larger amount of HZSM-5 (acid catalyst) and activated carbon (base catalyst) were used, the liquid biofuel yield decreased, including the organic and aqueous fractions. At a temperature range of $450-600^{\circ} \mathrm{C}$, the maximum liquid biofuel was achieved at $1 \mathrm{wt} . \%$ activated carbon (base catalysts). The optimum temperature with a variation of $1 \mathrm{wt} . \%$ activated carbon catalysts that produced the maximum liquid biofuel yield of $50.38 \mathrm{wt} . \%$ was $550^{\circ} \mathrm{C}$. This shows that the higher pyrolysis temperature improved bio-oil quality in the form of heat and hydrocarbon values. Still, it can also cause unwanted products such as polycyclic aromatic hydrocarbon (PAH) and nitrogen compounds (Li et al., 2017). However, several studies on pyrolysis with catalyst treatment would provide mixed results (Aysu et al., 2016). In addition, the choice of the catalyst in the pyrolysis process, both acid or base catalyst, should depend on the chemical structure and desired results. The literature revealed that acid catalysts in the pyrolysis process would increase char yield, while base catalysts would increase the liquid yield (Tripathi et al., 2016).

\subsection{Effect of Reaction Time on Pyrolysis Product Yields}

Figure $4 \mathrm{a}$ presents the relationship between the reaction time (i.e., 1-4 hours) at temperatures of $450-600^{\circ} \mathrm{C}$ and the aqueous fraction yield for each catalyst treatment. As shown, the longer the pyrolysis time, the higher the aqueous fraction yield is for all from 
catalyst treatment.

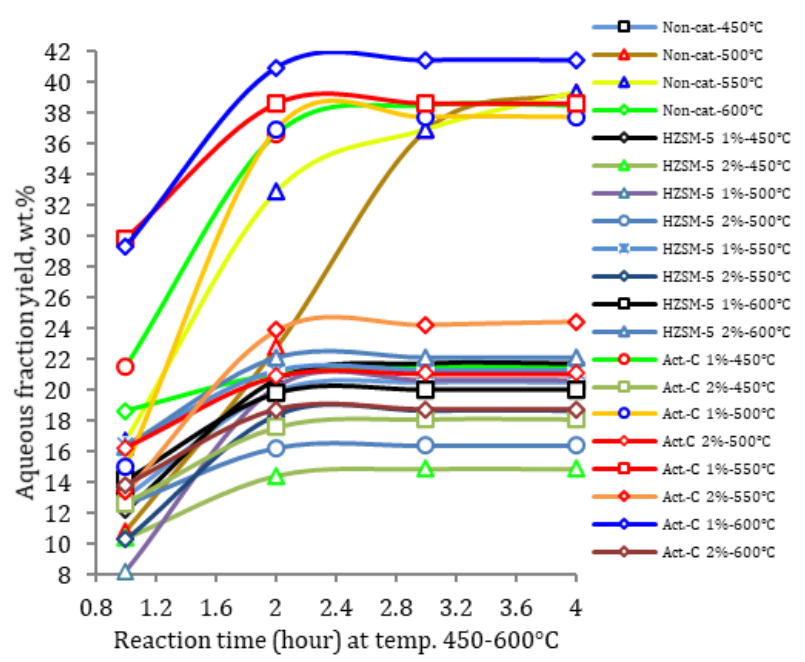

(a)

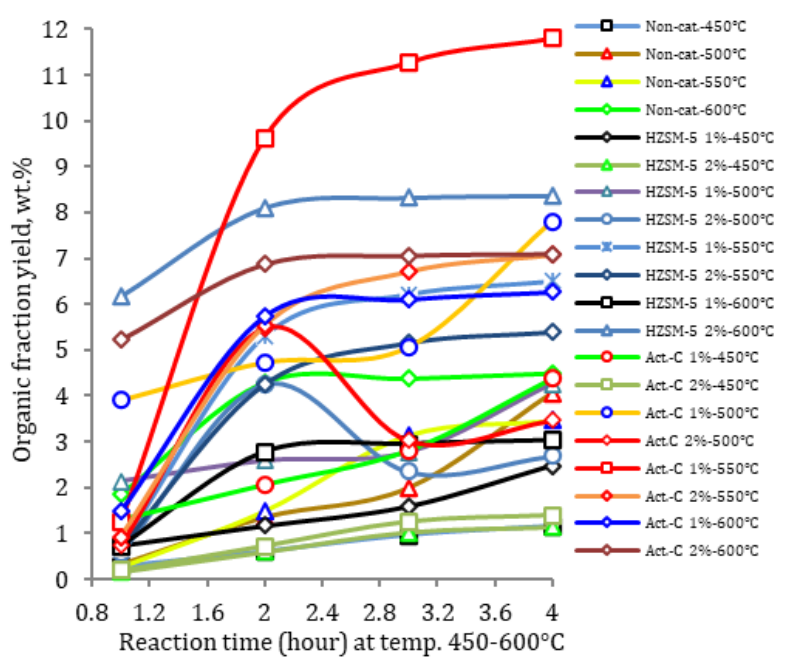

(b)

Figure 4 Effect of reaction time on (a) aqueous fraction; and (b) organic fraction

The optimal reaction time and temperature with 1 wt.\% activated carbon (base catalysts) product the maximum aqueous fraction yield (41.42 wt.\%) was 3 hours and $550^{\circ} \mathrm{C}$, respectively. Meanwhile, Figure $4 \mathrm{~b}$ shows the relationship between the reaction time (i.e., 1-4 hours) at a temperature of $450-600^{\circ} \mathrm{C}$ and organic fraction yield with the treatment of the catalyst. As shown, the longer the pyrolysis time and temperature, the fluctuating the organic fraction yield produced from all catalyst treatments. The optimal reaction time, temperature, and catalyst treatment necessary to create a maximum organic fraction yield of 11.27 wt. $\%-11.80$ wt.\% were $3-4$ hours, $550^{\circ} \mathrm{C}$, and 1 wt. $\%$ activated carbon, respectively. Compared to temperature, reaction time had a lower impact on product yield. Also, the aqueous fraction yield was influenced by temperature and type of catalyst, similar to that observed by Duan et al. (2013).

\subsection{Effect of Catalyst Type on Liquid Biofuel Yields}

Figure 5 shows that the non-catalyst, HZSM-5 catalyst (i.e., 1 wt.\%-2 wt.\%) and activated carbon catalysts (i.e., $1 \mathrm{wt} . \%-2 \mathrm{wt} . \%$ ), have different effects on the liquid biofuel yield. The liquid biofuel produced from $1 \mathrm{wt} . \%$ activated carbon (base catalyst) was greater than the one made from the non-catalyst, HZSM-5 catalyst ( 1 wt.\%-2 wt.\%), and 2 wt.\% activated carbon.

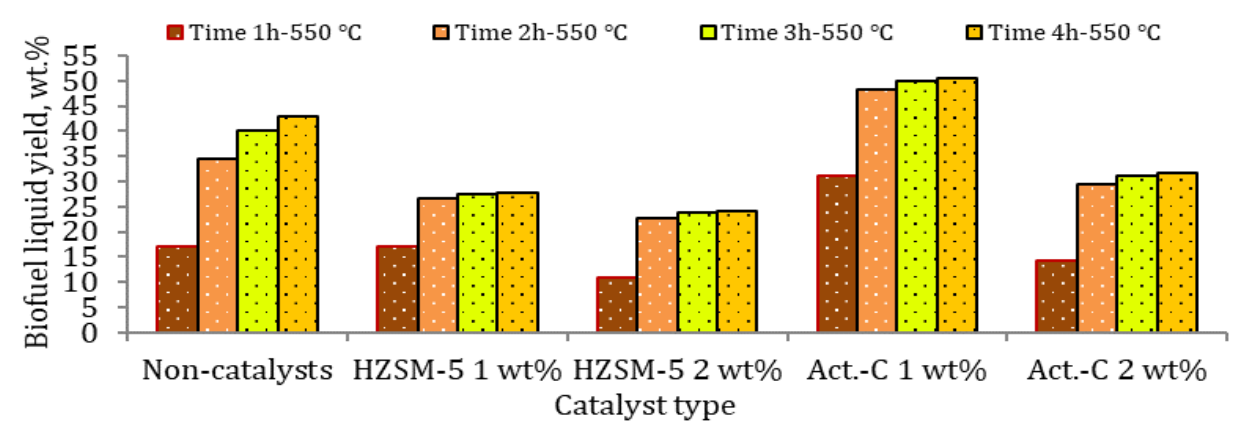

Figure 5 Effect of catalyst type on liquid biofuel yields

With the variable of the activated carbon (base catalyst), the maximum liquid biofuel yield of $50.38 \mathrm{wt} . \%$ was obtained with a $1 \mathrm{wt} \%$ catalyst; whereas with the variable of the HZSM5 (acid catalyst), the maximum liquid biofuel yield of 42.81 wt.\% was obtained with the 
non-catalyst treatment; the maximum liquid biofuel yield of $27.75 \mathrm{wt} . \%$ was obtained with 1 wt.\% HZSM catalyst. Besides increasing the water content in the liquid fraction, the catalyst increased the amount of char, especially at low temperatures. Higher temperatures reduced the aqueous fraction yield and increased the gas yield. This was caused primarily by an increase in the secondary cracking of oil vapor into incondensable gases. In several previous studies of catalytic pyrolysis, the addition of base catalysts increased the liquid yield. In contrast, the solid product increased in other studies, but the liquid and gas products decreased (Conti et al., 2016).

\subsection{Analysis of Characteristics of Liquid Biofuel Products}

\subsubsection{FTIR analysis}

Figure 6a shows the FTIR spectrum of the aqueous fraction of the biofuel. FTIR spectra from the aqueous fraction of the biofuel showed the presence of amine, alkene, alkene, and fluoro bonds at the peak of vibration. The test results showed that the peak with high intensity was at a wavelength of $1,632.42 \mathrm{~cm}^{-1}$, that is, the alkene group $(\mathrm{C}=\mathrm{C})$. In addition, the peak at $3,261.74 \mathrm{~cm}^{-1}$ can be interpreted as the vibration range of primary aliphatic amine $(\mathrm{N}-\mathrm{H})$ groups with moderate intensity, $1,408.75 \mathrm{~cm}^{-1}$ as the vibration range of fluoro compound $(\mathrm{C}-\mathrm{F})$, and $2,161.18 \mathrm{~cm}^{-1}$ as the vibration range of the alkyne $(\mathrm{C} \equiv \mathrm{C})$ with low intensity.

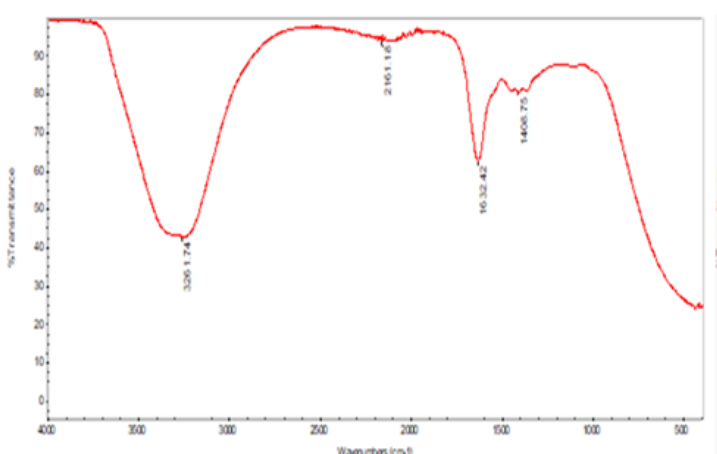

(a)

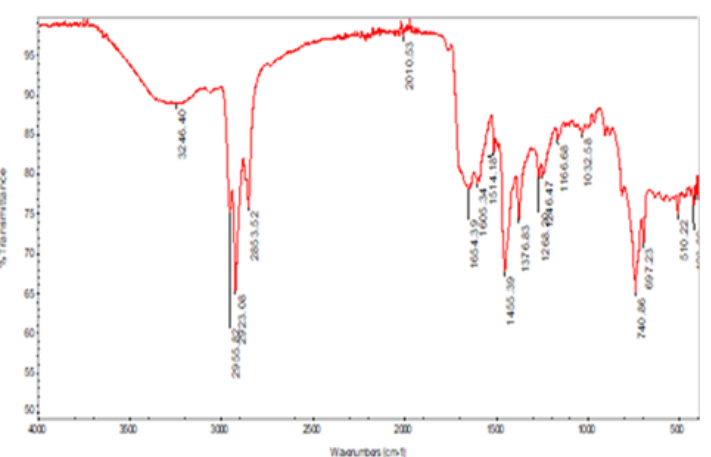

(b)

Figure 6 FTIR spectra: (a) Aqueous fraction; and (b) Organic fraction

Figure $6 \mathrm{~b}$ shows the FTIR spectrum of the organic fraction biofuel. The FTIR spectra from the organic fraction of the biofuel show the presence of carboxylic acid, alkane, isothiocyanate, cyclic alkanes, nitro compound, methyl, alkyl aryl ether, ester, sulfoxide, and halogen compound bonds. Figures $6 \mathrm{a}$ and $6 \mathrm{~b}$ show a peak with high intensity at a wavelength of $2,955.82 \mathrm{~cm}^{-1}$, namely the alkane group $(\mathrm{C} \equiv \mathrm{H})$. FTIR spectrophotometer analysis of the Chlorella sp. aqueous fraction based on a study by Du et al. (2011) revealed that it contains phenol $(\mathrm{O}-\mathrm{H})$ and amines $(\mathrm{N}-\mathrm{H})$ groups at a wavelength of $3,261.74 \mathrm{~cm}^{-1}$. In addition, the results of the FTIR spectrophotometer analysis of the organic fraction are also consistent with Du et al. (2011), showing that a wavelength of 3,000-2,500 $\mathrm{cm}^{-1}$ contains amines derived from carboxylic acid, a reaction amide and water. The same results were produced by Zainan et al. (2018) in catalytic pyrolysis of microalgae using base catalysts. Their findings show that the catalyst increases the selectivity of the compound and the composition of higher carbon content.

\subsubsection{Analysis of the density of liquid biofuel products}

Figure 7a shows the density of the aqueous fraction (i.e., 1-4 hours); with each catalyst treatment, the density decreased. The aqueous fraction density with the catalyst variations, non-catalyst, HZSM-5 catalyst (i.e., 1 wt.\%-2 wt.\%), and activated carbon catalyst (i.e., 1 wt.\%-2 wt.\%), ranged from 0.81-0.89 $\mathrm{kg} / \mathrm{L}$, satisfying most of the requirements as a 
number 2 type diesel biofuel, that is, $0.87-0.95 \mathrm{~kg} / \mathrm{L}$.

Figure $7 \mathrm{~b}$ shows the value of organic fraction density (i.e., 1-4 hours). In each catalyst treatment, the density value decreased. Organic fraction density in the catalyst variation was non-catalyst, HZSM-5 catalyst (i.e., 1 wt.\% $\%-2$ wt.\%), and activated carbon catalyst (i.e., $1 \mathrm{wt} . \%-2 \mathrm{wt} . \%$ ) at an interval of $0.65-0.70 \mathrm{~kg} / \mathrm{L}$. The type of catalyst treatment can affect the density of the resulting product. A decreasing density of the aqueous fraction (i.e., 1-4 hours) can be caused by the catalyst treatment. According to Williams and Horne (1995), catalysts reduce the oxygen content and increase the aromatic hydrocarbon content of liquid biofuel owing to their unique pore structure and high catalytic activity. This is because the catalytic pyrolysis of microalgae using base catalysts affects the quality of liquid biofuels. Various catalysts in the pyrolysis process with a specific reaction time affect the density. The longer the time of reaction, the better the density.

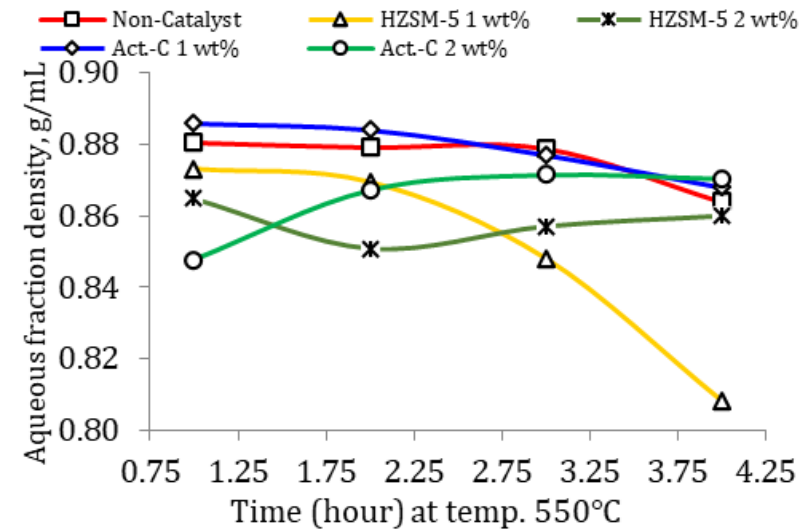

(a)

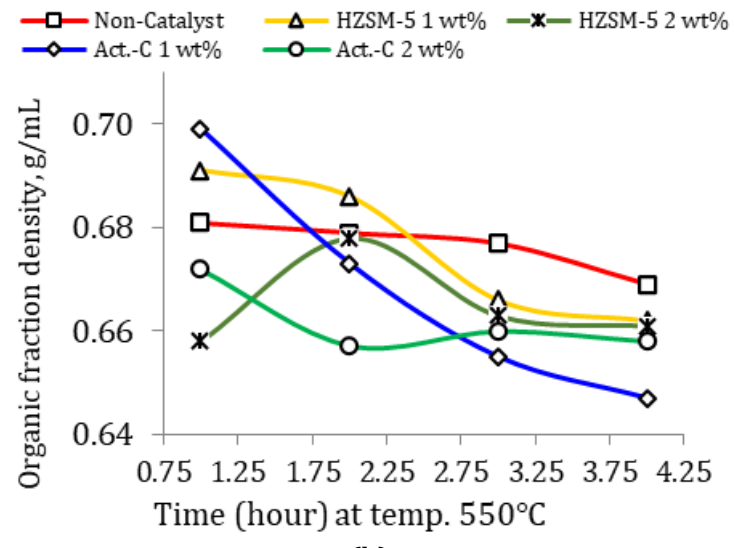

(b)

Figure 7 Effect of time on the density: (a) aqueous fraction; and (b) organic fraction

\subsubsection{Analysis of liquid biofuel viscosity}

Figure 8a shows the viscosity of the aqueous fraction (i.e., 1-4 hours) with each treatment variable, resulting in fluctuating values. The aqueous fraction viscosity for the variable $1 \mathrm{wt}$ \% activated carbon catalyst (i.e., $1-4$ hours) was 5.62-5.82 cSt.

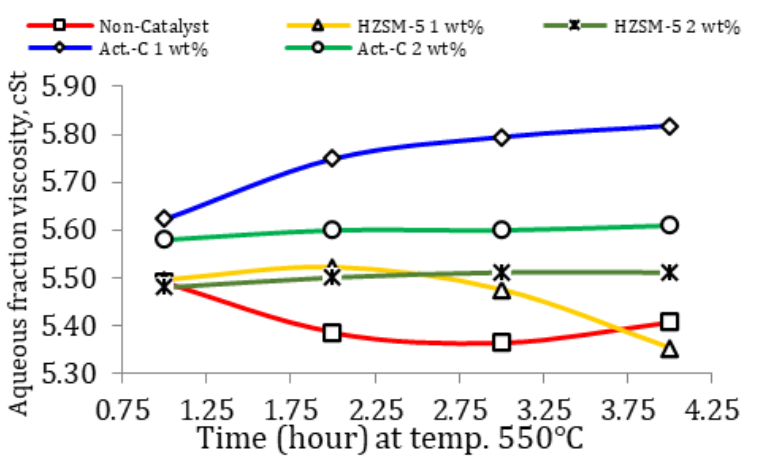

(a)

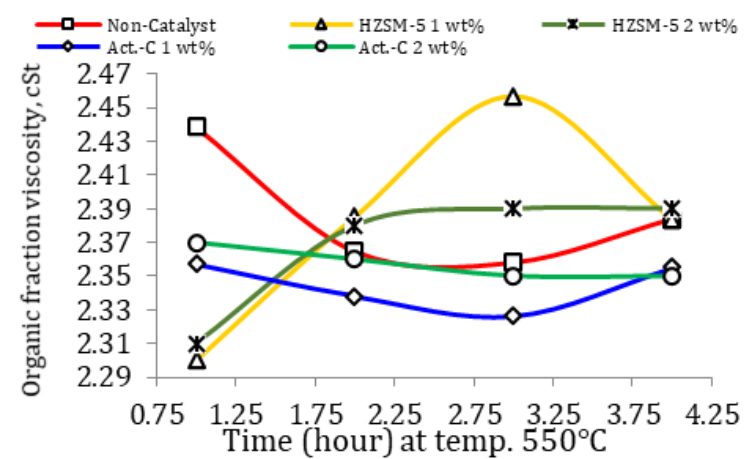

(b)

Figure 8 Effect of reaction time on the viscosity: (a) aqueous fraction; and (b) organic fraction

Figure 8a shows that the variable of the 1 wt.\% HZSM-5 (acid catalyst) treatment with pyrolysis time (i.e., 2-4 hours) decreased the viscosity from $5.52-5.35 \mathrm{cSt}$. Figure $8 \mathrm{~b}$ shows the viscosity of the organic fraction (i.e., 1-4 hours) with each treatment variable, resulting in fluctuating values. The organic fraction viscosity for the variable of $1 \mathrm{wt} . \%$ activated carbon catalyst (i.e., 1-4 hours) was 2.36-2.33 cSt. The results of the aqueous and organic fractions viscosity with each variable (i.e., HZSM 5.1 wt.\%, HZSM 5.2 wt.\%, Act 1 wt.\%, and 
Act 2 w.\%) showed that the viscosity values obtained in this study are consistent with the standard specifications for biodiesel following ASTM D445 (Amin et al., 2016). The existence of various catalysts in the pyrolysis process in a specific reaction time affects the viscosity of biofuels. The longer the time of reaction, the better the viscosity of biofuels.

\section{Conclusions}

The yield and quality of liquid biofuel from microalgae Chlorella sp. via slow catalytic pyrolysis is influenced by the type of catalyst (acid and base catalyst) and catalyst preparation method. The conditions for slow catalytic pyrolysis include temperature, catalyst amount of algae, type of catalyst, and the optimum reaction time for liquid biofuel yield. The maximum yield composed of aqueous and organic fractions is $550^{\circ} \mathrm{C}, 1 \mathrm{wt} . \%$ activated carbon catalyst and 3 hours. The characteristics of liquid biofuels in chemical composition, density, and viscosity at optimum process conditions show that the type of catalyst and catalyst preparation method affects the yield and quality of the product.

\section{Acknowledgements}

This work was financially supported by the Indonesian Ministry of Research, Technology and Higher Education (RISTEK-DIKTI) through the basic research of higher education excellence scheme.

\section{References}

Alaswad, A., Dassisti, M., Prescott, T., Olabi, A.G., 2015. Technologies and Developments of Third Generation Biofuel Production. Renewable and Sustainable Energy Reviews, Volume 51, pp. 1446-1460

Amin, A., Gadallah, A., El Morsi, A.K., El-Ibiari, N.N., El-Diwani, G.I., 2016. Experimental and Empirical Study of Diesel and Castor Biodiesel Blending Effect, On Kinematic Viscosity, Density and Calorific Value. Egyptian Journal of Petroleum, Volume 25(4), pp. 509-514

Aysu, T., Maroto-Valer, M.M., Sanna, A., 2016. Ceria Promoted Deoxygenation and Denitrogenation of Thalassiosira Weissflogii and its Model Compounds by Catalytic InSitu Pyrolysis. Bioresource Technology, Volume 208, pp. 140-148

Conti, R., Pezzolesi, L., Pistocchi, R., Torri, C., Massoli, P., Fabbri, D., 2016. Photobioreactor Cultivation and Catalytic Pyrolysis of the Microalga Desmodesmus Communis (Chlorophyceae) for Hydrocarbons Production by HZSM-5 Zeolite Cracking. Bioresource Technology, Volume 222, pp. 148-155

Dai, M., Xu, H., Yu, Z., Fang, S., Chen, L., Gu, W., Ma, X., 2018. Microwave-Assisted Fast CoPyrolysis Behaviors and Products between Microalgae and Polyvinyl Chloride. Applied Thermal Engineering, Volume 136, pp. 9-15

Du, Z., Li, Y., Wang, X., Wan, Y., Chen, Q., Wang, C., Lin, X., Liu, Y., Chen, P., Ruan, R., 2011. Microwave Assisted Pyrolysis of Microalgae for Biofuel Production. Bioresource Technology, Volume 102(7), pp. 4890-4896

Duan, P., Bai, X., Xu, Y., Zhang, A., Wang, F., Zhang, L., Miao, J., 2013. Non-Catalytic Hydropyrolysis of Microalgae to Produce Liquid Biofuels. Bioresource Technology, Volume 136, pp. 626-634

Hosseini, S.M., Saifoddin, A., Shirmohammadi, R., Aslani, A., 2019. Forecasting of $\mathrm{CO}_{2}$ Emissions in Iran based on Time Series and Regression Analysis. Energy Reports, Volume 5, pp. 619-631

$\mathrm{Hu}, \mathrm{Z} ., \mathrm{Ma}, \mathrm{X}$, Li, L., Wu, J., 2014. The Catalytic Pyrolysis of Microalgae to Produce Syngas. Energy Conversion and Management, Volume 85, pp. 545-550 
Hu, Z., Zheng, Y., Yan, F., Xiao, B., Liu, S., 2013. Bio-Oil Production through Pyrolysis of BlueGreen Algae Blooms (BGAB): Product Distribution and Bio-Oil Characterization. Energy, Volume 52, pp. 119-125

Kusdianto, K., Widiyastuti, W., Shimada, M., Nurtono, T., Machmudah, S., Winardi, S., 2019. Photocatalytic Activity of ZnO-Ag Nanocomposites Prepared by a One-Step Process using Flame Pyrolysis. International Journal of Technology, Volume 10(3), pp. 571-581

Li, G., Xiang, S.N., Ji, F., Zhou, Y.G., Huang, Z.G., 2017. Thermal Cracking Products and Bio-Oil Production from Microalgae Desmodesmus sp. International Journal of Agricultural and Biological Engineering, Volume 10(4), pp. 198-206

Mahfud, M., Kalsum, U., Aswie, V., 2020. Biodiesel Production through Catalytic Microwave In-situ Transesterification of Microalgae (Chlorella sp.). International Journal of Renewable Energy Development, Volume 9(1), pp. 113-117

Mostafazadeh, A.K., Solomatnikova, O., Drogui, P., Tyagi, R.D., 2018. A Review of Recent Research and Developments in Fast Pyrolysis and Bio-Oil Upgrading. Biomass Conversion and Biorefinery, Volume 8, pp. 739-773

Pattiya, A., 2011. Bio-oil Production via Fast Pyrolysis of Biomass Residues from Cassava Plants in a Fluidised-Bed Reactor. Bioresource Technology, Volume 102, pp. 1959-1967

Pattiya, A., Sukkasi, S., Goodwin, V., 2012. Fast Pyrolysis of Sugarcane and Cassava Residues in a Free-Fall Reactor. Energy, Volume 44(1), pp. 1067-1077

Pourkarimi, S., Hallajisani, A., Alizadehdakhel, A., Nouralishahi, A., 2019. Biofuel Production Through Micro-And Macroalgae Pyrolysis - A Review of Pyrolysis Methods and Process Parameters. Journal of Analytical and Applied Pyrolysis, Volume 142, https://doi.org/10.1016/j.jaap.2019.04.015

Rizzo, A.M., Prussi, M., Bettucci, L., Libelli, I.M., Chiaramonti, D., 2013. Character of Microalg Chlorella as a Fuel and its Thermogravimetric Behavior. Applied Energy, Volume 102, pp. 24-31

Shihab, M.A., Dhahir, M.A., Mohammed, H.K., 2020. Kinetic Study of Air BubblesCetyltrimethylammonium Bromide (CTAB) Surfactant for Recovering Microalgae Biomass in a Foam Flotation Column. International Journal of Technology, Volume 11(3), pp. 440-449

Supramono, D., Jonathan., Haqqyana., Setiadi., Nasikin M., 2016. Improving Bio-Oil Quality through Co-Pyrolysis of Corn Cobs and Polypropylene in a Stirred Tank Reactor. International Journal of Technology, Volume 7(8), pp. 1381-1391

Thahir, R., Altway, A., Juliastuti, S.R., Susianto., 2019. Production of Liquid Fuel from Plastic Waste using Integrated Pyrolysis Method with Refinery Distillation Bubble Cap Plate Column. Energy Reports, Volume 5, pp. 70-77

Tripathi, M., Sahu, J.N., Ganesan, P., 2016. Effect of Process Parameters on Production of Biochar from Biomass Waste through Pyrolysis: A Review. Renewable and Sustainable Energy Reviews, Volume 55, pp. 467-481

Williams, P.T., Horne, P.A., 1995. The Influence of Catalyst Regeneration on the Composition of Zeolite Upgraded Biomass Pyrolysis Oils. Fuel, Volume 74(12), pp. 1839-1851

Yang, C., Li, R., Zhang, B., Qiu, Q., Wang, B., Yang, H., Ding, Y., Wang, C., 2019. Pyrolysis of Microalgae: A Critical Review. Fuel Processing Technology, Volume 186, pp. 53-72

Yuwono, A.H., Arini, T., Lalasari, L.H., Sofyan, N., Ramahdita, G., Nararya, A., Firdiyono, F., Andriyah, L., Subhan, A., 2017. The Effect of Various Precursors and Solvents on the Characteristics of Fluorine-Doped Tin Oxide Conducting Glass Fabricated by Ultrasonic Spray Pyrolysis. International Journal of Technology, Volume 8(7), pp. 1336-1344

Zainan, N.H., Srivatsa, S.C., Li, F., Bhattacharya, S., 2018. Quality of Bio-Oil from Catalytic Pyrolysis of Microalgae Chlorella Vulgaris. Fuel, Volume 223, pp. 12-19 